\title{
Trust Evaluation Model for Supply Chain Enterprises under Blockchain Environment
}

\author{
Xia Jiang ${ }^{1, a^{*}}$ and Yongjun Liu ${ }^{1, b}$ \\ ${ }^{1}$ School of Management, Wuhan University of Technology, Wuhan, P.R. China, 430070 \\ a1225291642@qq.com; b 494244991@qq.com
}

\begin{abstract}
Keywords: Blockchain; Supply Chain; Trust Evaluation Model; The joint credibility; The Association Credibility
\end{abstract}

\begin{abstract}
Blockchain is considered to be a disruptive innovation of the computing model after mainframe, personal computer, and it has become the necessary technology sustain of information sharing and effective cooperation for supply chain. To research on the problem of trust evaluation among supply chain enterprises, through introducing four factors of transaction satisfaction, product ability, risk probability of information concealment and reward and penalty factor, a trust evaluation model to evaluate enterprises' joint credibility and association credibility under blockchain environment was presented.
\end{abstract}

\section{Introduction}

Blockchain is an innovative application of computer technology, such as distributed data storage, peer-to-peer transmission, consensus mechanism and encryption algorithm [1]. And it's also a disruptive innovation of the computing model after mainframe, personal computer. In supply chain, blockchain has solved the two main points based on its features of transparence, traceability and irreversibility of transactions data. The two points are: (1) Inefficiency and difficulty to proof and claim responsibility because of the information lack of transparency and propagation fluency; (2) Fake and shoddy products can't be eliminated on account of the logistics' features of multi regions and longer periods.

In traditional supply chain management (SCM), supply chain trust refers to the probability that an enterprises predict its cooperative partner will deliver on its promises under unknown circumstances, and its evaluation has become the hot area. Based on the reputation mechanism, estimation method of Bayesian probability was used to estimate the credit value of supply chain and recommendation, and the comprehensive evaluation model of credit value between enterprises partners was obtained [2]. Applying Markov process and Cauchy satisfaction function, and through selecting five indicators of measuring trust, namely reputation, Willing to be customer-oriented, Number of cooperative objects, scale and Sharing confidential information, the model of trust mechanism in supply chain enterprises was established, in which the trust value was calculated by the transition probability[3]. A transaction satisfaction evaluation method based on fuzzy theory was proposed by NIU [4], which was evaluated from three aspects: product quality, product costs and completion time. On this basis, a reputation-based direct trust evaluation model that contained five factors of transaction satisfaction, transaction amount, transaction time, transaction number and reward and penalty factor was established. A trust model of hybrid P2P supply chain based on interest group in order to improve the confidence crisis in the supply chain among enterprises was proposed by [5].

In this paper, under the blockchain environment, the supply chain trust refers to the degree of trust of an enterprise to another enterprise. Differ from the traditional environment, the performance was showed in 3 aspects. (1) The deal is performed automatically by the intelligent contract, so the execution probability of contract trading is $100 \%$; (2) The trading data is transparent and traceable, so the utilization value of the indirect transactions and the default price increases; (3) The status of enterprises is equal under blockchain environment. The features of blockchain, peer-to-peer network, no third party or centralized management node, show the equality of enterprises. Based on 
the three points, a trust evaluation model of supply chain is constructed from two dimensions, direct and indirect.

\section{The Joint Credibility Evaluation Model}

According to the object of study, the trust is divided into joint credibility and association credibility [6]. The Joint Credibility (JC) is built on the historical behaviors and performance that come from the interactions among enterprises. Four factors of transaction satisfaction [4], product ability, risk probability of information concealment [6] and reward and penalty factor [4] were introduced to evaluate the joint credibility based on the previous research and the transaction's features of traceability and transparency.

(1)The transaction satisfaction. It refers to the degree of satisfaction of the two parties in the transaction. The function of $\mathrm{S}_{\mathrm{k}}\left(\mathrm{i}, \mathrm{j}, \mathrm{t}_{\mathrm{k}}\right)$ denotes the transaction satisfaction of the Kth transaction between enterprise $\mathrm{i}$ and enterprise $\mathrm{j}$ at the current time. The time attenuation function $\varphi\left(t_{k}\right)$ which satisfies the equation of $\varphi\left(t_{k}\right)=e^{-\frac{1}{\alpha t_{k}}}$ is introduced to reflect the feature of the trust attenuation with the time. The unit of $t_{k}$ in function $\varphi\left(t_{k}\right)$ is month, and the constraint condition of $t_{k}$ is $0<t_{k} \leq 120$. In the function $\varphi\left(t_{k}\right), \alpha$ is the time attenuation coefficient, and it satisfies the constraint of 0 . Therefore the revised formulation of degree of satisfaction is $\frac{\sum_{\mathrm{k}=1}^{\mathrm{m}} \varphi\left(\mathrm{t}_{\mathrm{k}}\right) \mathrm{S}_{\mathrm{k}}\left(\mathrm{i}, \mathrm{j}, \mathrm{t}_{\mathrm{k}}\right)}{\sum_{\mathrm{k}=1}^{\mathrm{m}} \varphi\left(\mathrm{t}_{\mathrm{k}}\right)}$.

(2)The product ability. It refers to the ability of enterprises to provide products. The function of $P_{k}\left(i, j, t_{k}\right)$ denotes the probability of the enterprise $i$ believes enterprise $j$ is able to provide products according to the promise at the time $t_{k}$. Similar to the evaluation of transaction satisfaction, the time attenuation function $\varphi\left(t_{k}\right)$ is introduced in consideration of the relationship between product ability and time. Therefore the revised formulation of product ability is $\frac{\sum_{\mathrm{k}=1}^{\mathrm{m}} \varphi\left(\mathrm{t}_{\mathrm{k}}\right) \mathrm{P}_{\mathrm{k}}\left(\mathrm{i}, \mathrm{j}, \mathrm{t}_{\mathrm{k}}\right)}{\sum_{\mathrm{k}=1}^{\mathrm{m}} \varphi\left(\mathrm{t}_{\mathrm{k}}\right)}$.

(3) The risk probability of information concealment (p). The greater of risk probability of information concealment, the smaller the value of trust is [6]. However, under blockchain environment, the enterprises can't conceal their transaction information, but they may don't choose to reveal the occurrence of the accidents actively in order to reduce losses, such as natural disasters led to damage to the factory buildings.

(4) The reward and penalty factor used to punish the failure of the transaction. Under the blockchain environment, it's possible that the enterprise can't meet the contract's items due to speculation or occurrence of accidents. Because the failure of the transactions are broadcast in whole network under the blockchain environment, the value of this factor is bigger than the value under traditional conditions. Defined a threshold $\delta$ as standard to decide whether the enterprises should be punished. When an enterprise should be rewarded, the value of transaction satisfaction must satisfy the constraint $S_{k}\left(i, j, t_{k}\right)>\delta$ and $f(m)=e^{-\frac{1}{\sqrt{m}}}$. When an enterprise should be punished, the value of transaction satisfaction must satisfy the constraint $\mathrm{S}_{\mathrm{k}}\left(\mathrm{i}, \mathrm{j}, \mathrm{t}_{\mathrm{k}}\right)<\delta$ and $f(m)=e^{-\frac{1}{m}}$. Of course, when $S_{k}\left(i, j, t_{k}\right)=\delta$ and $f(m)=1$, the enterprise shouldn't be punished or rewarded.

The formulation of joint credibility is Eq. 1 .

$$
\mathrm{JC}\left(\mathrm{i}, \mathrm{j}, \mathrm{t}_{\mathrm{k}}\right)=\left[\mathrm{f}(\mathrm{m}) \frac{\sum_{\mathrm{k}=1}^{\mathrm{m}} \varphi\left(\mathrm{t}_{\mathrm{k}}\right) \mathrm{S}_{\mathrm{k}}\left(\mathrm{i}, \mathrm{j}, \mathrm{t}_{\mathrm{k}}\right) \mathrm{P}_{\mathrm{k}}\left(\mathrm{i}, \mathrm{j}, \mathrm{t}_{\mathrm{k}}\right)}{\sum_{\mathrm{k}=1}^{\mathrm{m}} \varphi\left(\mathrm{t}_{\mathrm{k}}\right)}\right]^{\mathrm{p}}
$$

\section{The Association Credibility Evaluation Model}

The association credibility (AC) refers to the degree of trust between two relevant enterprises without direct transactions. The relationship among enterprise $i$, enterprise $j$, and relevant enterprises are showed in Fig. 1. 


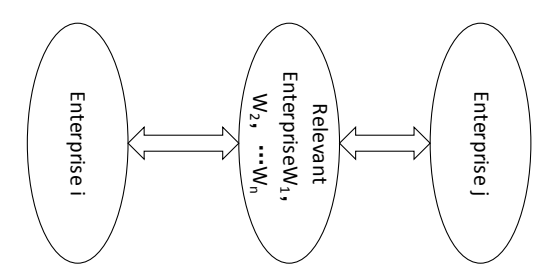

Figure 1. The association credibility

The supply chain network composes two parts, the supply chain link with products as core and the interactive network of all enterprises produced by the interaction of products. Under traditional environment, the whole trading was led by the core node in the supply chain link. And the enterprises that don't have direct transactions will save the trading information separately, so the value of trust can't be evaluated until with the help of the object assessment of the relevant enterprises. Obviously, the evaluation method is lack of practical and scientific. Meanwhile, the evaluation model in traditional environment ignores the impact of transaction on trust in interactive network, which makes the whole evaluation model incomplete.

Because of the transparency of information under the blockchain environment, the evaluation of trust between indirect enterprises can be carried out based on the actual transaction information, which is more scientific. The fact that all transactions are saved in the same account and all transactions are transparent to all nodes in the network makes it possible evaluate the association credibility according to the path from enterprise $\mathrm{i}$ to enterprise $\mathrm{j}$. And the following two scenarios should be taken into account:

(1)Different enterprises has different weight $w_{i}\left(i, j, t_{k}\right)$. The higher credibility the enterprises has, the more cautious the enterprises will be when choose their partner. So, compared with the low credibility of the enterprise, the partners of enterprises that has high credibility may deserve more trustworthy. On the other hand, the closer of trading relationship of two enterprises, the more trust should be obtained for the enterprises. A weight value $w_{i}\left(i, j, t_{k}\right), w_{i}=f\left(D I\left(i, j, t_{k}\right) * e^{-\varepsilon n}\right.$ is used in this paper, The variable $\varepsilon$ denotes the relevant enterprises attenuation coefficient, and it satisfies the constraint of $0<\varepsilon<1$.

(2) The risk probability of information concealment (p) also has effect on the association credibility. The concealment of enterprise information is concealed by all other enterprises, so the risk brought by it is disseminated.

The formulation of association credibility is equation Eq.2.

$\mathrm{AC}=\frac{(1-\mathrm{p}) \sum_{\mathrm{i}=1}^{\mathrm{m}} \sum_{\mathrm{i}=1}^{\mathrm{n}} \mathrm{w}_{\mathrm{i}}\left(\mathrm{i}, \mathrm{j}, \mathrm{t}_{\mathrm{k}}\right) * \mathrm{DI}\left(\mathrm{i}, \mathrm{j}, \mathrm{t}_{\mathrm{k}}\right)}{\mathrm{n}}$

In the Eq.2, the variable $\mathrm{m}$ denotes the number of path from enterprise $\mathrm{i}$ to enterprise $\mathrm{j}$, and the variable $\mathrm{n}$ denotes the number of relevant enterprises in every path.

Finally, the trust of the enterprises in supply chain is Eq.3, and the variable $\beta$ denotes the weight of the joint credibility.

$\mathrm{I}=\beta \mathrm{JC}+(1-\beta) \mathrm{AC}$

\section{Results of Simulation}

In this paper, the simulation of product ability in Eq. 1 and the association credibility in equation Eq. 3 are carried out. The following content is the results of experiments and analysis.

Experiment 1, The effect of product ability on joint credibility. In order to reduce the effect of time, value of the variable $\alpha$ is fixed at 0.002 . And the threshold $\delta$ of trading satisfaction is fixed at 0.5 , the risk probability of information concealment is fixed at 0.6 . The experiment's results of experiment was showed in Fig. 2. 


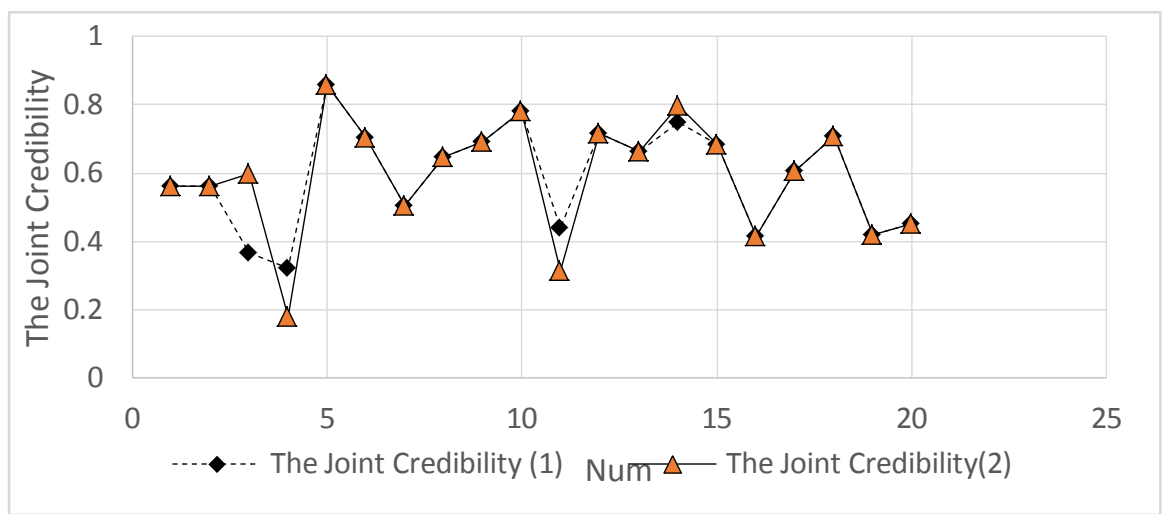

Figure 2. Results of experiment 1

From Fig.2, several conclusions can be acquired. Under the same conditions, the stronger the ability of the enterprise to provide products, the greater the degree of joint credibility. Meanwhile, under the same conditions of product ability, the greater the degree of transaction satisfaction and the smaller the reward and penalty factor is, the greater the joint credibility will be. For example, in the experiment 2 th and 8th, when the value of transaction satisfaction is 0.6 and 0.8 , and the value of product ability is 0.8 , the value of joint credibility is 0.561 and 0.648 .

Experiment 3, the association credibility on trust. The value of joint credibility is fixed at 0.8 . The risk probability of information concealment is fixed at 0.6 . The relevant enterprises attenuation coefficient $\varepsilon$ is fixed at 0.4 , and the weight of the joint credibility $\beta$ is fixed at 0.6 . At the same time, we supposed the path from enterprise $i$ to enterprise $j$ is 1 . The experiment's results of experiment was showed in Fig. 3.

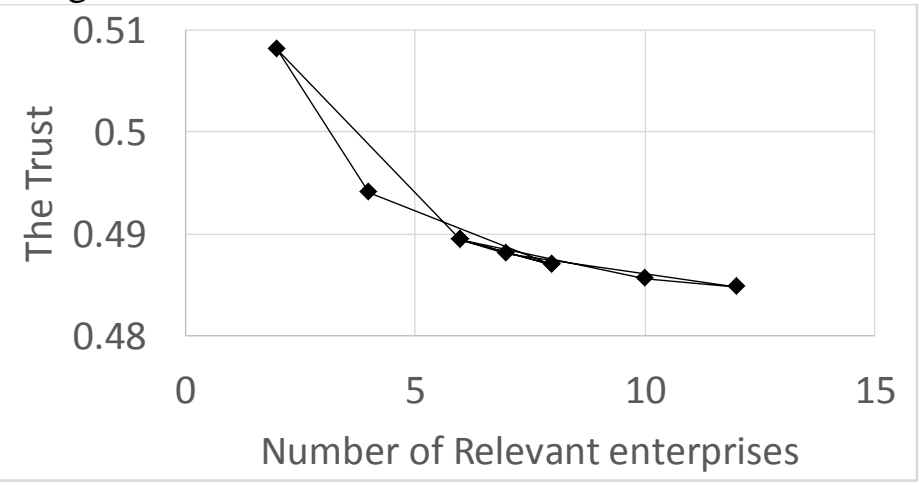

Figure 3. Results of experiment 3

According to Fig. 3, in the same conditions, with the increasing of the number of relevant enterprises, the degree of trust is decreasing. However, the positive effect isn't remarkable. When the number of relevant enterprises is 2 and 12, the value of trust is 0.5081 and 0.4847 , so the difference is only 0.0234 .

\section{Conclusion}

In view of the features of information, namely transparency, traceability, irreversibility and undeniableness, a trust evaluation model to evaluate enterprises' joint credibility and association credibility under blockchain environment was presented. The model includes four factors, namely transaction satisfaction, product ability, the risk probability of information concealment and the reward and penalty factor. Through simulation, we verified that the product ability has positive effect on joint credibility. And we also found the transaction satisfaction has moderated effect on joint credibility.

The main problem was researched in this paper is the trust evaluation of supply chain among enterprises under blockchain environment, and only four factors were introduced into the model. In 
the future research, goodwill can be taken into consideration. Meanwhile, due to the limitation of the author's ability, the simulation analysis of multi-dimensional factors can't be completed.

\section{References}

[1] Christidis K, Devetsikiotis M, Blockchains and Smart Contracts for the Internet of Things, J. IEEE Access. 4(2016)2292-2303.

[2] ZHUO Xiang-zhi, WANG Xu, DAI Ying, Credit assessment model for supply chain alliance between partners enterprises, J. Computer Integrated Manufacturing Systems. 15 (2009)1946-1950.

[3] LIN Qiang, NAREN Gao-wa, XU Wen-ting, Trust Mechanism Based on Process in Supply Chain Enterprise Cooperation, J. Journal of Tianjin University (Social Sciences). 14(2012)193-197.

[4] NIU Jingchun, SHEN Limin, Reputation-based direct trust evaluation model of supply chain enterprises,J. Computer Integrated Manufacturing Systems. 21(2015) 2732-2738.

[5] WANG Lei, HUANG Meng-xing, A trust model of hybrid P2P supply chain based on interest group, J. Microelectronics \& Compute. 30(2013)78-82.

[6] ZHANG Shuang, GONG Ming, KANG Zhuang, The influence of information hiding risk on the trust and performance of supply chain enterprises, J. Reform of Economic System. 5(2013)163-166. 